\title{
Exhaust emissions from modes of transport under actual traffic conditions
}

\author{
J. Merkisz ${ }^{1}$, M. Jacyna ${ }^{2}$, A. Merkisz-Guranowska ${ }^{1}$ \& J. Pielecha ${ }^{1}$ \\ ${ }^{I}$ Poznan University of Technology, Poland \\ ${ }^{2}$ Warsaw University of Technology, Poland
}

\begin{abstract}
The paper characterizes state-of-the-art PEMS (Portable Emission Measurement System) equipment for exhaust emissions measurement under actual operating conditions. This equipment allows for measurement of the exhaust emissions from all modes of transport. In addition, the paper contains the results of exhaust emission research for engines of a variety of transport applications such as light duty vehicles, heavy-duty vehicles or non-road vehicles (farm tractors, groundwork and forest machinery). Own exhaust emission research results performed under different traffic conditions of new motor vehicles fuelled with different fuels (gasoline, diesel fuel and natural gas) have been compared with the type approval values that define the vehicle emission indexes. The analysis has been performed in relation to a vehicle but the proposed measurement methodology is also knitted to the engine operating conditions. The testing of heavy-duty vehicles described in the book was divided into several stages for which the results obtained for these vehicles were compared for loaded and unloaded vehicles. Ecological advantages of the city buses of different powertrain configurations have been determined (diesel, hybrid) on selected regular bus lines in the city center.

Keywords: exhaust emission, portable emission measurement system, real road conditions.
\end{abstract}

\section{Introduction}

Literature analysis in the field of exhaust emissions research allows distinguishing two kinds of analytical research from the point of view of its aims [1]. These are: 
- Comparative research of the exhaust emissions from passenger vehicles, heavy-duty vehicles or combustion engines alone. These could be investigations conducted on a chassis or engine dynamometer using equipment used for on-board measurements [2]. Such investigations enable an evaluation of the exhaust emissions using the on-board methodology. These could also be comparative investigations of the exhaust emissions from vehicles fueled with different fuels including alternative fuels;

- Research aiming at the assessment of the emission indexes by determining of the gaseous exhaust emissions values from a given category of vehicles under actual traffic conditions (on-board measurements) and comparing them with the admissible exhaust emissions (Euro). Such indexes enable the assessment of the gaseous exhaust emissions from the discussed vehicles under actual traffic conditions [3, 4]).

Currently, a growing stress is put on the measurements of exhaust emissions, particularly from combustion engines of vehicles and machinery under actual conditions of operation (Fig. 1). These measurements, despite being realized on a selected sample of modes of transport, much better reflect the actual situation than the test procedures simulating the actual conditions of operation or stationary tests. They became possible thanks to the recent advancement of the measurement techniques. The advancement of these techniques also provided the possibility of measurement of very little concentrations of the emission components in the exhaust gas (Fig. 2).
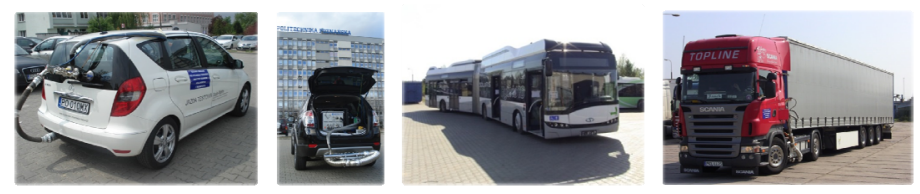

The transport sector as a source of air pollution

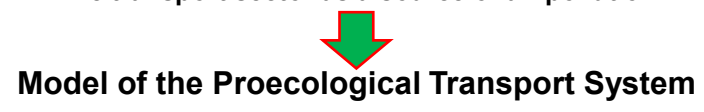

Figure 1: Aim of the research on the vehicle exhaust emissions.

The fundamental differences between stationary exhaust emissions tests and tests under actual traffic conditions are as follows:

- Chassis dynamometer: testing the whole vehicles on reproducible parameters,

- Engine dynamometer: testing engines only, no relation to the actual traffic conditions of a heavy-duty vehicle.

Under actual traffic operation variability of conditions occurs that have impact on the exhaust emissions:

- Ambient air temperature, pressure, humidity, weather conditions (wind, rain, snow etc.),

- Quality of the road surface,

- Traffic states, traffic obstacles,

- Driving style: aggressive, normal and preferred - eco-driving. 
1. Gaseous exhaust emissions (CO, HC, NOx)

- Semtech DS, firmy Sensors

- Ecostar, firmy Sensors

- M.O.V.E., firmy AVL

2. Particle mas (PM) \& number (PN) emissions

- Micro Soot Sensor (AVL)

- Ecostar PM (Sensors)

- Particle Counter (AVL)

- Ecostar PN (Sensors)

- EEPS (TSI)
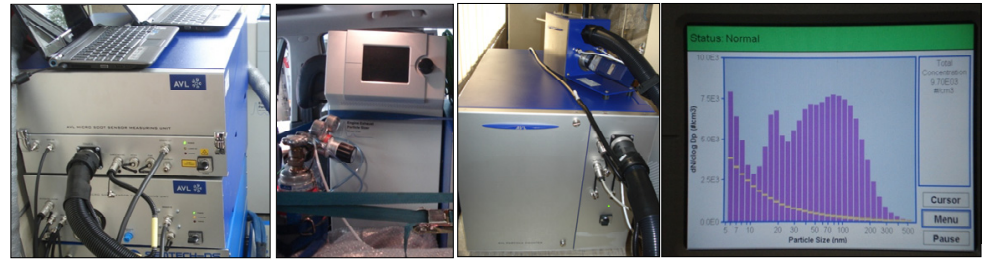

Figure 2: Exhaust emissions measurement equipment.

The authors of the paper propose an introduction of the emission indexes denoting the multiplicity of the increase or decrease of the exhaust emissions under actual traffic conditions compared to the homologation tests [5]. Such an index for a given exhaust component has been defined as follows:

$$
\mathrm{k}_{\mathrm{j}}=\frac{\mathrm{E}_{\text {real, } \mathrm{j}}}{\mathrm{E}_{\mathrm{NEDC}\left(\mathrm{ETC}_{\mathrm{N}, \text { WHT }), j}\right.}}
$$

where:

$\mathrm{j}$ - exhaust component for which the emission index was determined,

$\mathrm{E}_{\mathrm{real}, \mathrm{j}}$ - emission rate under actual traffic conditions $[\mathrm{g} / \mathrm{s}]$,

$\mathrm{E}_{\mathrm{NEDC}, \mathrm{j}}$ - emission rate measured in the NEDC test $[\mathrm{g} / \mathrm{s}]$ or other tests such as those for heavy-duty vehicles (ETC, WHTC).

The exhaust emission rate under actual operating conditions can be calculated using the vehicle operating time share characteristics $u(a, V)$ and the emission rate characteristics for $a j$-th exhaust component $e_{j}(a, V)$ expressed in grams per second:

$$
\mathrm{E}_{\mathrm{real}, \mathrm{j}}=\sum_{\mathrm{a}} \sum_{\mathrm{v}} \mathrm{u}(\mathrm{a}, \mathrm{V}) \cdot \mathrm{e}_{\mathrm{j}}(\mathrm{a}, \mathrm{V})
$$

If there is no information on the vehicle exhaust emissions in the homologation test, admissible values according to the Euro emissions standard can be assumed for a given vehicle. The values of the admissible exhaust emissions for a given exhaust component expressed in $\mathrm{g} / \mathrm{km}$ ( or $\mathrm{g} / \mathrm{kWh}$ ) can be converted into the values of the exhaust emission rate (in $\mathrm{g} / \mathrm{s}$ ), knowing the 
duration (e.g. $\left.\mathrm{t}_{\mathrm{NEDC}}=1180 \mathrm{~s}\right)$ and the covered distance $\left(\mathrm{e} . \mathrm{g} . \mathrm{S}_{\mathrm{NEDC}}=11,007 \mathrm{~m}\right)$ in the homologation test. Such relations serve the purpose of determining the exhaust emissions presented in the further part of the paper.

\section{Testing of passenger vehicles}

The conducted tests regarding the exhaust emissions from passenger vehicles fitted with combustion engines (gasoline, diesel, Euro 2-Euro 5 compliant - Fig. 3) under actual traffic conditions were the first validation of the values and usefulness of the developed tool - a universal on-board exhaust emissions measurement system. Determining the level of emissions under actual traffic conditions and comparing it with the values obtained on the chassis dynamometer in the homologation test led to the calculation of the emission index.

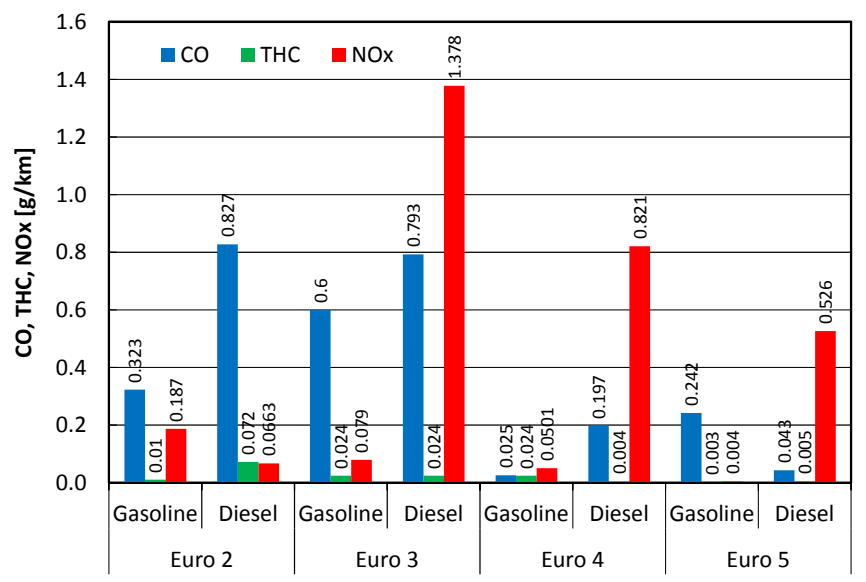

Figure 3: Comparison of the vehicle exhaust emissions using different vehicle emission categories.

The determined emission index serves the purpose of providing information whether the exhaust emission under actual traffic conditions is comparable with the exhaust emissions during the homologation test. At the same time, it is a validation of the driving conditions in the homologation test (developed many years ago) compared to the actual traffic conditions.

From the analysis of data presented in Fig. 3 it follows that the emission values obtained under actual traffic operation are exceeded for diesel engines while for spark ignition engines, the results do not provide a clear answer compared to the values assumed from the emission standard. The authors confirm the variability of the measurement values for different test routes: for carbon monoxide and hydrocarbons it is $\pm 60 \%$, nitric oxides $\pm 50 \%$ (depending whether cold start or hot start measurements were realized) and for the emission 
of carbon dioxide $\pm 30 \%$ (lower values for extra urban cycles and greater values for the urban cycles).

For vehicles fitted with alternative drivetrains, greater exhaust emissions were observed when aftermarket LPG system was applied (Fig. 4). The emission indexes obtained for vehicles fueled with gasoline and CNG (Fig. 5) characterize the vehicle on-road exhaust emission level in comparison to the exhaust emission standard applicable for this vehicle [6]. Following the assumption of CNG as the primary fuel - the indexes of the exhaust emissions of a vehicle fueled with gasoline are much worse: the value of the carbon monoxide index for gasoline $\left(\mathrm{k}_{\mathrm{CO}}=3.9\right)$ proves an excessive emission (four times the Euro 4 standard) for this vehicle. The outstanding values of the emission index (for hydrocarbons and nitric oxides) do not exceed the values prescribed in the emission legislation.

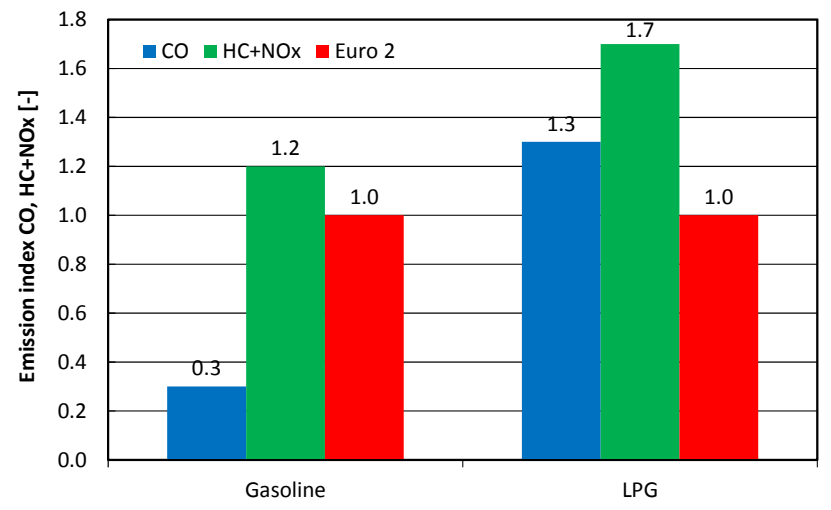

Figure 4: Comparison of the exhaust emissions from vehicles fueled with gasoline and LPG (spark ignition engines).

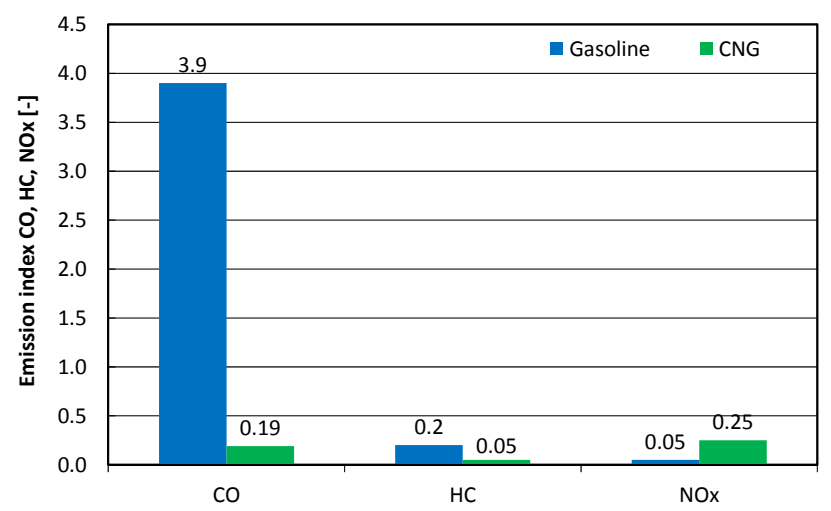

Figure 5: Comparison of the exhaust emissions from vehicles fueled with gasoline and CNG (spark ignition engines). 
Significant ecological advantages are observed for hybrid vehicles only in urban conditions for which the exhaust emissions are five times lower that that prescribed in the emission standard (Fig. 6). In the extra urban conditions, the efficiency of the hybrid powertrain drops as the average vehicle speed increases and the total time of stops decreases (Fig. 7).
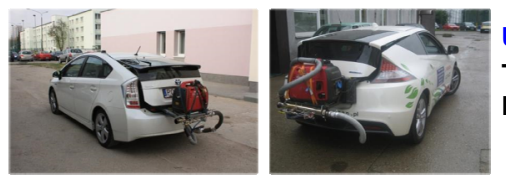

Urban traffic

Time: $13^{\circ 0}-15^{\circ 0}$

Length route: $30 \mathrm{~km}$

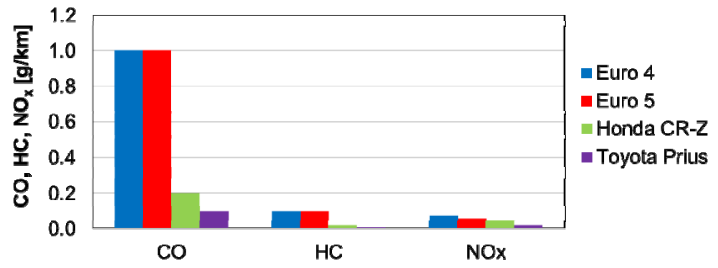

Figure 6: Comparison of the exhaust emissions of hybrid vehicles fitted with spark ignition engines.

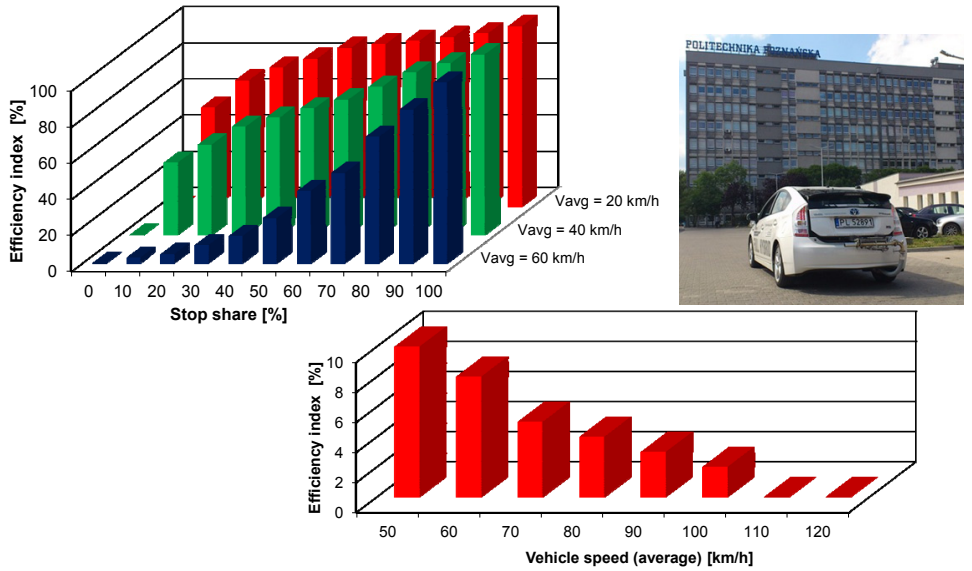

Figure 7: Efficiency index (relative reduction of fuel consumption).

\section{Testing of heavy-duty vehicles}

For many years, the system of vehicle inspections for exhaust emissions included type approvals and production compliance. Currently, stress is put on the exhaust emissions measurements (particularly for heavy-duty vehicles) under transient operating states that much better simulate the actual traffic conditions than the 
stationary tests. In the new legislation, the life cycle of a vehicle has significantly been extended expressed in the vehicle mileage within which the vehicle must comply with the emission standards. Heavy-duty vehicles of the gross vehicle weight exceeding $16,000 \mathrm{~kg}$ will have to comply with the emission standards up to $700,000 \mathrm{~km}$. This will cause a significant tightening of the quality requirements for components having impact on the exhaust emissions such as catalytic converters and diesel particulate filters. The investigations of the influence of the vehicle load on the exhaust emission for heavy-duty vehicles indicate that the emission grows almost twice (Fig. 8).

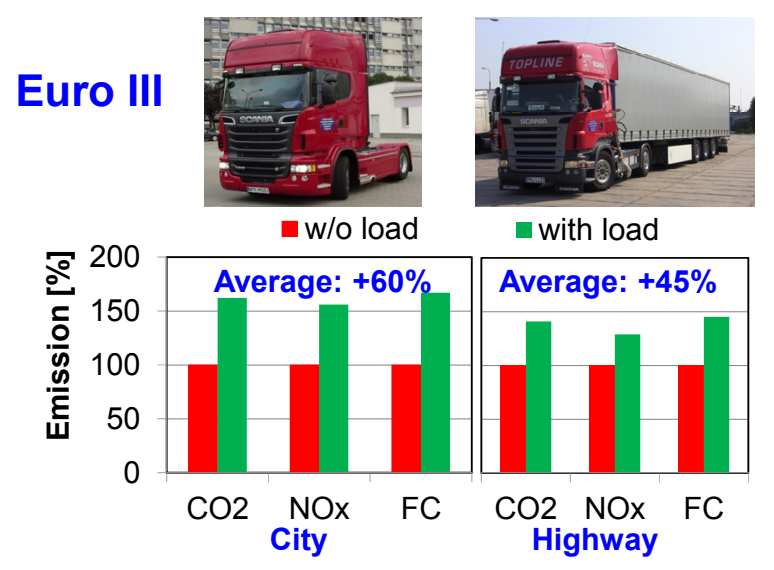

Figure 8: Exhaust emissions test results for heavy-duty vehicles.

The emission level of city buses, due to the specificity of their use, can only be assessed during actual conditions of their operation. The most suitable tests for these buses are performed on the urban routes. Using a portable exhaust emission measurement system, the authors measured the emission level of a hybrid and a conventional bus in city traffic in the city of Poznan. The conditions were selected to enable the most accurate reflection of the actual traffic conditions: the traffic on the selected bus route was in line with the average traffic of the Poznan city routes. The objects of the tests were Solaris conventional and hybrid buses (Fig. 9). The buses were selected for their similarities and to enable a comparison of their functionality and ecological performance under actual traffic conditions (the bus engines complied with the Euro 5 standard).

For the tested buses, the emission indexes were determined - the actual emissions of the conventional and the hybrid buses were compared with the values prescribed in the EEV standard. The obtained data on the unit emissions were compared with the transient test (ETC). From the analysis of the emission indexes calculated for the vehicles with different drivetrains (Fig. 10) in the ETC test it follows that parallel and serial hybrid vehicles have the $\mathrm{CO}$ emission index lower than 1. It is noteworthy that the emission index for nitric oxides exceeded the admissible limit for the bus fitted with the conventional drivetrain (maximum 


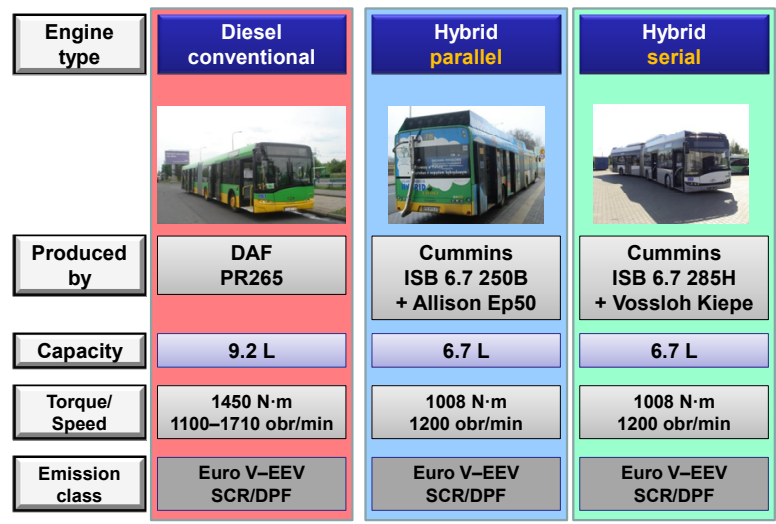

Figure 9: Characteristics of the tested objects - city buses.

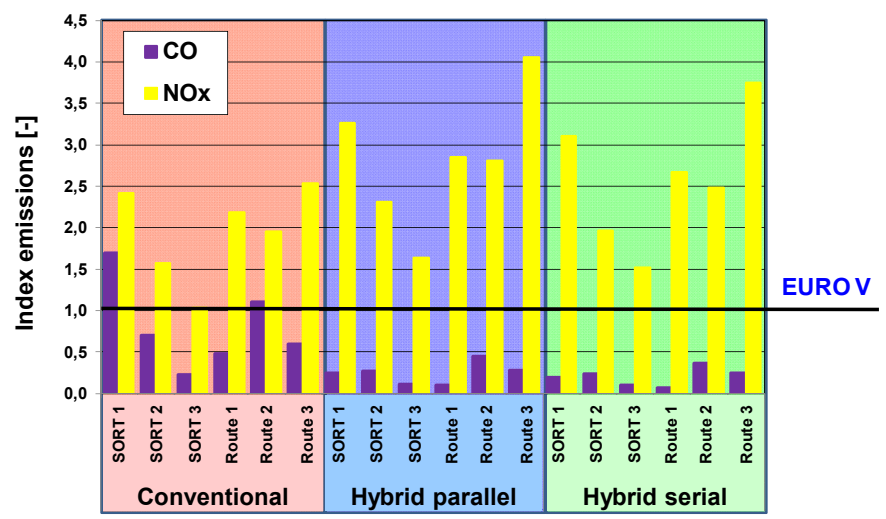

Figure 10: $\quad \mathrm{CO}$ and $\mathrm{NO}_{\mathrm{x}}$ emission indexes of the buses were determined based on data on the actual on-road emission and assuming the admissible values according to different homologation tests (EEV standard) in the ETC test.

value) 2.5 times and up to 4 times for the hybrid buses. This confirms a lower conversion rate of the selective catalytic reduction system. This may have been caused by the mismatched SCR as far as the engine operating characteristics are concerned.

\section{Testing of non-road vehicles}

Another area of the exhaust emission testing is non-road vehicles and machinery. The tests were performed, inter alia, on farm tractors and utility trucks. From the exhaust emissions tests performed under actual conditions of fieldwork operation 
(Fig. 11) it follows that the engines of these machines mainly operate at a steady engine speed (which facilitates the reduction of the exhaust emissions) while the engine load varies. These conditions are different from the ones in the homologation tests [7].

The tests were performed on a farm tractor and a pick-up truck. Based on the performed tests under actual conditions of operation the authors confirmed that the truck has better ecological performance than the farm tractor (Fig. 12).

1. Cargo transport $(4,000 \mathrm{~kg})$, farm tractor and a pick-up truck

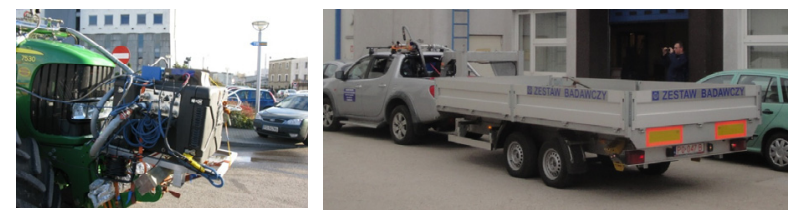

2. Cargo transport $(20,000 \mathrm{~kg})$, farm tractor and a heavy-duty truck
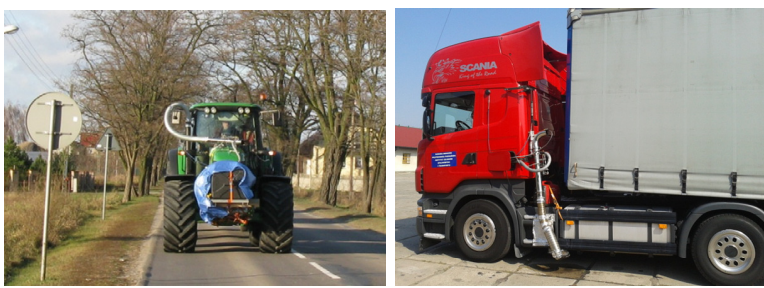

Figure 11: Comparative research into the exhaust emissions of the transport sets.

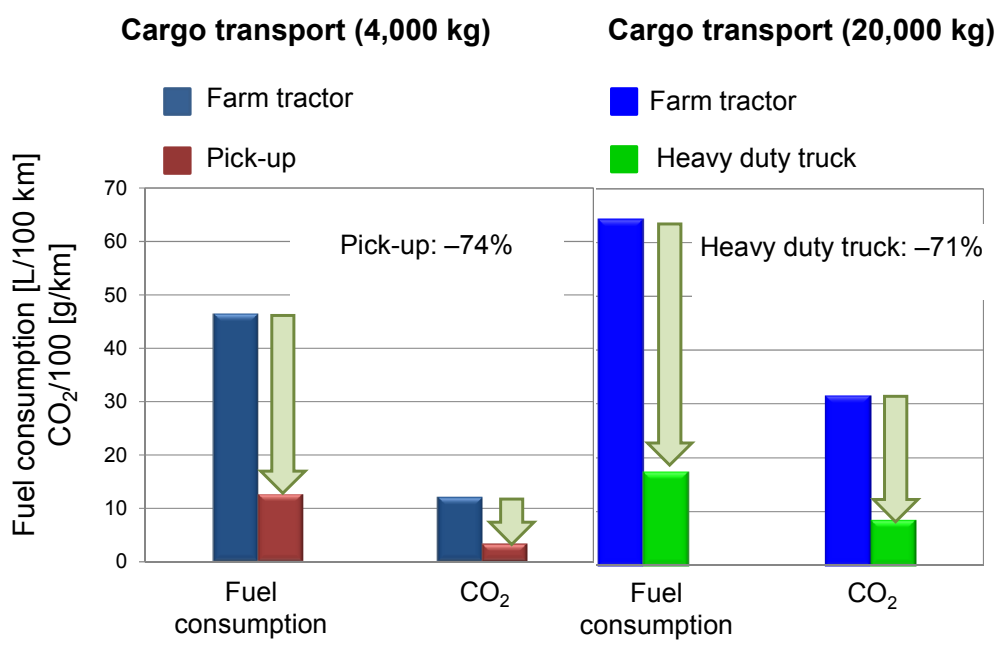

Figure 12: Fuel consumption/ $\mathrm{CO}_{2}$ emission - test of non-road vehicles. 
Analyzing the on-road emissions from the entire run it was observed that the onroad emission of the truck was lower and that of the farm tractor was many times higher. The greatest differences were recorded for the on-road emission of CO (for the farm tractor this was more than 25 times higher, $\mathrm{HC}-11$ times higher and $\mathrm{NO}_{\mathrm{X}}$ almost 6 times higher.) Except the on-road emission of $\mathrm{CO}$ of the utility truck the exhaust emission of all the exhaust components, for both the pick-up truck and the farm tractor exceeded the limits prescribed in the Euro 4 standard. That also includes the fuel consumption $\left(\mathrm{CO}_{2}\right.$ emission) for the farm tractor (Fig. 12) - almost three times in excess as compared to the utility truck.

\section{Conclusions}

For the realization of the exhaust emissions tests under actual conditions of operation the authors used the testing potential of portable exhaust emissions analyzers measuring all exhaust components (gaseous components and particulate matter mass and size distribution from spark ignition and diesel engines fueled with different fuels). The use of data from the on-board emissions measuring system in conjunction with the diagnostic system of an individual transport unit, based on the definable emission index, allows the assessment of the ecological performance of a vehicle in operation. The authors propose a monitoring system of all means of transport for the assessment of the ecological performance of entire groups of vehicles varying in terms of date of production (i.e. exhaust emission limits), their period of operation or conditions of operation. The emission indexes for vehicles are defined as multiplicity of the increase/reduction of the exhaust emissions during operation compared to the homologation tests designed for a given vehicle category complying with prescribed standards of emission of: carbon monoxide, hydrocarbons, nitric oxides and particulate matter (mass and size). Based on the created index for the individual modes of transport we may determine the models of exhaust emissions for different vehicles (or stationary machines) under actual conditions of operation. This will allow an ongoing monitoring of machinery fitted with combustion engines working under actual conditions of operation.

This is a unique exploratory achievement, as in the US, attempts to implement such tests for heavy-duty vehicles are still in the stage of development while for passenger vehicles the developed concept and testing methodology is pioneer worldwide $[8,9]$.

The proposed correction factors will adapt the homologation emission values obtained in the tests to the actual traffic conditions of a vehicle. Hence, the factors, referred to as ' $k$ ', should be dimensionless and determined for different emission categories:

- Passenger and light-duty trucks (up to 3,500 kg) - for which the emission limits are prescribed in grams per kilometer $[\mathrm{g} / \mathrm{km}]$,

- Heavy-duty and non-road vehicles - for which the emission limits are prescribed in grams per kilowatt hour $[\mathrm{g} / \mathrm{kWh}]$. 
The authors of the paper propose an introduction of exhaust emission index $k$, correcting the values of the homologation emissions to the value obtained under actual operation:

- For passenger vehicles and light-duty trucks (up to 3,500 kg):

$$
\mathrm{m}=\mathrm{kEN} \mathrm{S}
$$

where:

$\mathrm{m}$ - mass of the pollutant $[\mathrm{g}]$,

$\mathrm{k}$ - actual emission coefficient,

E - road emission of a vehicle according to the Euro standard [g/km],

$\mathrm{N}$ - number of vehicles,

$\mathrm{S}$ - vehicle mileage $[\mathrm{km}]$.

- For heavy-duty vehicles and non-road vehicles (in excess of 3.5 tons):

$$
\mathrm{m}=\mathrm{kEN} \mathrm{W}
$$

where:

$\mathrm{m}$ - mass of the pollutant $[\mathrm{g}]$,

$\mathrm{k}$ - actual emission coefficient,

E - unit emission of a vehicle according to the Euro standard [g/kWh],

$\mathrm{N}$ - number of vehicles,

$\mathrm{W}$ - engine operation on a road portion [kWh] (the value of work can be pulled from the vehicle OBD system).

\section{References}

[1] Johnson, T.V., Review of diesel emissions and control. SAE Technical Paper Series 2010-01-0301, 2010.

[2] Commission Regulation (EC) No 692/2008 of 18 July 2008 implementing and amending Regulation (EC) No 715/2007 of the European Parliament and of the Council on type approval of motor vehicles with respect to emissions from light passenger and commercial vehicles (Euro 5 and Euro 6) and on access to vehicle repair and maintenance information. OJ L 199/1, 28.7.2008.

[3] Johnson, K., Durbin, T., Cocker, D., Miller, J., Agama, R., Moynahan, N., Nayak, G., On-road evaluation of a PEMS for measuring gaseous in-use emissions from a heavy-duty diesel vehicle. SAE Technical Paper Series 2008-01-1300, 2008.

[4] Khalek, I., Status update on the PM-PEMS measurement allowance project. Sensors 5th Annual SUN (SEMTECH User Network) Conference, Ann Arbor 2008.

[5] Merkisz, J., Pielecha, J., Radzimirski, S., New Trends in Emission Control in the European Union, Springer Tracts on Transportation and Traffic, Vol. 1, 2014. 
1150 Energy Production and Management in the 21st Century, Vol. 2

[6] Pielecha, J., Merkisz, J., Łabędź, K., The effect of mileage of the vehicle fueled with natural gas on the vehicle's ecological indices. Combustion Engines, No. 3, 2013.

[7] Merkisz, J., Lijewski, P., Fuć, P., Pielecha, J., Exhaust emission tests from agricultural machinery under real operating conditions. SAE Technical Paper Series 2010-01-1949, 2010.

[8] Seger, J.P., Vehicle integration for US EPA 2010 emissions and lowest cost of ownership. SAE Technical Paper Series 2010-01-1956, 2010.

[9] Quan, H., ARB's Stockton heavy-duty vehicle laboratory and portable emission monitoring system (PEMS) activities. Sensors 5th Annual SUN (SEMTECH User Network) Conference Ann Arbor 2008. 